\title{
Effect of L-arginine on Markers of Metabolic Syndrome Related to Abdominal Obesity and Disorder of Lipid Metabolism in Female Wistar Albino Rats
}

\author{
Egbuonu A. C. Cemaluk*, Ezeanyika L. U.S \\ Department of Biochemistry, University of Nigeria Nsukka, Enugu State, Nigeria
}

\begin{abstract}
Metabolic syndrome (MES) (a cluster of features indicating metabolic disorders), is associated with a significant reduction in nitric oxide, NO, a major metabolite of L-arginine (ARG). Abdominal obesity and lipid disorder are among the risk factors whereas female gender is an independent risk factor for the development of MES in animals. Therefore, the aim of this study is to ascertain the effect of ARG on markers of MES related to abdominal obesity and disorder of lipid metabolism, using female Wistar albino rats as model. Two groups of female rats were given a single dose of $3 \mathrm{ml} / \mathrm{kg}$ body weight (bw) of distilled water, DW, and $60 \mathrm{mg} / \mathrm{kg}$ bw of ARG, respectively as control and treated groups. Exposing ARG to female rats evoked a non-significant increase $(\mathrm{p}>0.05)$ in waist circumference $(13.00 \pm 0.84 \mathrm{~cm})$ and waist:stature ratio $(0.43 \pm 0.04)$ but a significant increase $(\mathrm{p}<0.01)$ in triacylglycerol to high density lipoprotein cholesterol (TAG:HDL-chol) ratio (3.46 \pm 0.06$)$ of the rats, suggesting abdominal obesity that may worsen metabolic syndrome (MES) in the animals. The exposure elicited a significant increase $(\mathrm{p}<0.01)$ in the concentration of total cholesterol (T-chol) $(69.36 \pm 0.24 \mathrm{mg} / 100 \mathrm{ml})$, HDL-chol $(26.20 \pm 0.47 \mathrm{mg} / 100 \mathrm{ml})$, low density lipoprotein cholesterol (LDL-chol) $(1.41 \pm 0.50 \mathrm{mg} / 100 \mathrm{ml})$ and triacyglycerol (TAG) $(90.77 \pm 0.13 \mathrm{mg} / 100 \mathrm{ml})$ in the rats' serum. These indicate adverse influence on lipid metabolism, and possibly on MES related to disorder of lipid metabolism in the female rats. In conclusion, this study suggests that ARG aggravated the markers of MES related to abdominal obesity and lipid metabolism in the female rats. This negates the hoped-for potential of ARG in the management of MES in animals.
\end{abstract}

Keywords Metabolic Syndrome, Abdominal Obesity, Lipid Metabolism, L-Arginine, Waist:Stature Ratio

\section{Introduction}

Abdominal obesity is an important cardiovascular risk factor and was among the listed components of metabolic syndrome (MES)[1]. Abdominal obesity or high waist circumference and lipid disorder are among the risk factors for the development of MES in animals[2]. In particular, lipids are atherogenic and the deposition of plaques in the blood vessels following their increase narrows the blood vessels resulting to high blood pressure or hypertension which is a major component of MES.

Metabolic syndrome is a cluster of cardiovascular risk factors that is characterized by obesity, atherogenic dyslipidemia, and hypertension[3,2]. It is not a disease entity but a cluster of medical disorders in an individual that could predispose animals to further health challenges. The further health challenges include type 2 diabetes mellitus[4,5], cancer[6-9] and obstructive sleep apnea[10].

\footnotetext{
* Corresponding author:
}

tonycemalukegbuonu@yahaoo.com (Egbuonu A.C. Cemaluk)

Published online at http://journal.sapub.org/ajb

Copyright (C) 2012 Scientific \& Academic Publishing. All Rights Reserved
Therefore, MES could contribute to significant premature mortality[11]. Its scourge is pandemic, and the pattern cuts across every age, location and gender hence is of global public health concern[12,13]. However, MES is more prevalent in developed nations, urban areas, female gender and with increasing age than otherwise[14,15].

The association of a significant reduction in NO with the pathophysiology of MES[16] suggested that L-arginine (ARG), a major precursor in the synthesis of $\mathrm{NO}$ [17], may improve MES in animals. Obesity and lipid metabolism are linked through the activity of insulin. This is because insulin, the key hormone in the regulation of glucose homeostasis, is the main pathogenic factor of type 2 diabetes mellitus and the main feature of obesity which are major components of MES [18]. Essentially, insulin stimulates glucose transport, uptake and utilization by cells; inhibits hepatic gluconeogenesis; and decreases adipose-tissue lipolysis and hepatic production of very-low-density lipoproteins[2].

The present study aimed to ascertain the effect of ARG on markers of MES related to abdominal obesity and lipid metabolism. This study sought to achieve the stated aim through the set objectives of studying the effect of ARG on the waist circumference, waist:stature ratio and concentration of total 
cholesterol, high density lipoprotein cholesterol, low density lipoprotein cholesterol and triacylglycerol, using female rats as model. This is because these parameters are good indicators of features and risk factors of components of MES, including diabetes mellitus, cardiovascular diseases and obesity.

\section{Materials and Methods}

\subsection{Chemicals and Reagents}

The chemicals used in this study were of analytical grade and were products of reputable companies based in Europe and America.

\subsection{Concentration Determination/Justification}

The test concentration, ARG (60 mg/kg body weight, bw) was calculated and adjusted based on the WHO reported daily ARG oral intake [19] and the concentration used in earlier studies [20, 21, 22, 23].

\subsection{Equipment/Instruments}

The Department of Biochemistry, University of Nigeria, Nsukka and Bishop Shanahan Memorial Hospital, Nsukka provided standard equipment and instruments used in the course of this study. These include the following, Bench centrifuge(Wisterfuge model 1384), UV/Vis Spectrophotometer (JENWAY 6205), Spectrophotometer (NOVASPEC LKB Biochrome, model 4049, Germany).

\subsection{Experimental Design}

\subsubsection{Animals and Treatment}

Procurement of female weanling Wistar rats used in this study was from the animal house of the Faculty of Biological Sciences University of Nigeria, Nsukka. The rats weighed $60-80 \mathrm{~g}$. The animal study was according to International guidelines for the care and use of laboratory animals in Biomedical Research[24].

The rats acclimatized for a week and immediately thereafter were randomized into two groups with sample size of eight rats each. Group B rats were exposed to ARG (60 $\mathrm{mg} / \mathrm{kg} \mathrm{bw}$ ) whereas Group A rats were given distilled water (DW) $(3 \mathrm{ml} / \mathrm{kg} \mathrm{bw})$. Exposure route was by oral intubation, which was consecutive for 28 days.

The rats, housed in a well-ventilated stainless steel cages at room temperature $\left(28 \pm 2^{\circ} \mathrm{C}\right)$ and tropical humid condition, were maintained under standard natural photoperiodic condition of twelve hours of light alternating with twelve hours of darkness. In compliance with the ethical guidelines for treating laboratory animals, the rats were allowed unrestricted access to tap water and standard rat chow (Grand Cereals and Oil Mills Limited, Jos, Nigeria) for the experimental period.
The animals were fasted overnight before sacrifice after 28 days. Collection of the respective blood samples of animals was by ophthalmic venous plexus or retro orbital sinus venipuncture. This involved inserting a sterile capillary tube into the medial canthus of the eye of the rat to puncture the retro-bulbar plexus resulting in out flow of blood into clean non-anticoagulated glass sample tubes.

Centrifugation of clotted blood at $3000 \mathrm{rpm}$ for 10 minutes yielded the serum. Thereafter, the serum (aspirated separately into stoppered polystyrene tubes) was stored in a deep freezer for subsequent use in determining the selected serum biochemical markers of metabolic syndrome (total cholesterol, high density lipoprotein cholesterol and triacylglycerol concentrations).

\subsection{Parameters Determined}

\subsubsection{Serum Total Cholesterol Concentration (T-Chol) Concentration}

The serum total cholesterol concentration determination was by the method of Zlatkis et al.[25]. The method is based on the principle that the reaction of both cholesterol and cholesterol esters with ethanol and the hydrochloric acid $(\mathrm{HCl})$ in chromogen could yield color of equal absorbancies measured at $550 \mathrm{~nm}$.

\subsubsection{Serum High Density Lipoprotein Cholesterol (Hdl-Chol) Concentration}

This was estimated by the method as described[26]. This method based on the principle that chylomicrons, very low density lipoprotein (VLDL) and low density lipoprotein (LDL) are precipitated by phosphotungstic acid in the presence of magnesium, leaving high densisty lipoprotein (HDL) in solution. The colorimetric reading was at $560 \mathrm{~nm}$.

\subsubsection{Serum Low Density Lipoprotein Cholesterol (LDL-Chol) Concentration}

Serum LDL-chol concnetrationn estimation was from the relationship as given by Ochei and Kolhatkar[26] thus:

LDL-chol $(\mathrm{mg} / 100 \mathrm{ml})=$ Total cholesterol $-(\mathrm{HDL}-\mathrm{chol}+$ $0.46 \times \mathrm{TAG})($ All in $\mathrm{mg} / 100 \mathrm{ml})$

\subsubsection{Serum Triacylglycerol (TAG) Concentration}

The serum TAG concentration determination was by the method of Calson[27]. This method based on the principle of colorimetric determination of glycerol (at $570 \mathrm{~nm}$ ) after alkaline hydrolysis of glycerides.

\subsubsection{Height (Stature) and Waist Circumference}

The height and waist circumference measurements of the rats were in centimeters before conversion to metres. The height was measured from nose slit to tail and the waist: stature ratio computed.

\section{Statistical Analysis}


Analysis of data to determine the significant differences in means was by Student's t-test, using the Statistical Package for the Social Sciences (SPSS) for Windows version 16.0 (SPSS Inc., Chicago, IL., USA). Results were expressed as mean and standard deviation (Mean $\pm \mathrm{SD}$ ) of eight rats per group at significance level of $\mathrm{p}<0.01$.

\section{Results}

\subsection{Waist Circumference}

The results of the present study reveal that rats exposed to ARG (Group B) had a non-significant $(\mathrm{p}>0.05)$ increase $(13.00 \pm 0.84 \mathrm{~cm})$ in their measured waist circumference relative to the control $(12.75 \pm 0.71 \mathrm{~cm})$ (Figure 1). The results show that the waist circumference of rats increased by only $1.96 \%$ in ARG-fed rats relative to the control.

\subsection{Waist: Stature Ratio}

The waist:stature ratio increased in the ARG-treated rats $(0.43 \pm 0.04)$ in contrast with the control $(0.42 \pm 0.03)$. The observed increase $(2.38 \%)$ in ARG-treated group relative to the control however was not statistically significant at 0.05 probability level (Figure 2).

\subsection{Serum Total Cholesterol (T-Chol) Concentration}

The serum T-chol concentration increased in rats given ARG $(69.36 \pm 0.24 \mathrm{mg} / 100 \mathrm{ml})$ when compared with control $(42.37 \pm 0.18 \mathrm{mg} / 100 \mathrm{ml})$. The observation (representing an increase of $63.70 \%$ ) was statistically significant at 0.01 probability level (Figure 3).

\subsection{Serum High Density Lipoprotein Cholesterol (HDL-Chol) Concentration}

The results of the present study as presented in Figure 4 reveal that the serum HDL-chol concentration increased in rats that were fed ARG $(26.20 \pm 0.47 \mathrm{mg} / 100 \mathrm{ml})$ as against the control $(24.47 \pm 0.73 \mathrm{mg} / 100 \mathrm{ml})$. The observed difference (representing an increase of $7.07 \%$ ) was statistically significant at 0.01 probability level.

\subsection{Serum Low Density Lipoprotein Cholesterol (LDL-Chol) Concentration}

A significant elevation $(\mathrm{p}<0.01)$ in serum LDL-chol concentration $(1.41 \pm 0.50 \mathrm{mg} / 100 \mathrm{ml})$ was observed in the ARG-fed rats compared with the control rats $(0.57 \pm 0.51$ $\mathrm{mg} / 100 \mathrm{ml})$. The increase in serum LDL-chol concentration observed in ARG-fed rats is $147.37 \%$ relative to the control (Figure 5).

\subsection{Serum Triacylglycerol (TAG) Concentration}

The serum TAG concentration results of this study, as depicted in Figure 6, increased in ARG-treated animals $(90.77 \pm 0.13 \mathrm{mg} / 100 \mathrm{ml})$ compared with the control (39.60土 $0.77 \mathrm{mg} / 100 \mathrm{ml})$. The observation was statistically signifi- cant at 0.01 probability level and represented an over one-fold increase (129.22\%) relative to the control.

\subsection{Serum Triacylglycerol to High Density Lipoprotein Cholesterol (TAG: HDL-Chol) Ratio}

The results of the present study as shown in Figure 7 reveal that the serum TAG: HDL-chol ratio of the ARGtreated rats $(3.46 \pm 0.06)$ increased $(\mathrm{p}<0.01)$ above that of the control rats (1.62 \pm 0.06$)$. This is an over one fold $(113.58 \%)$ increase relative to the control.

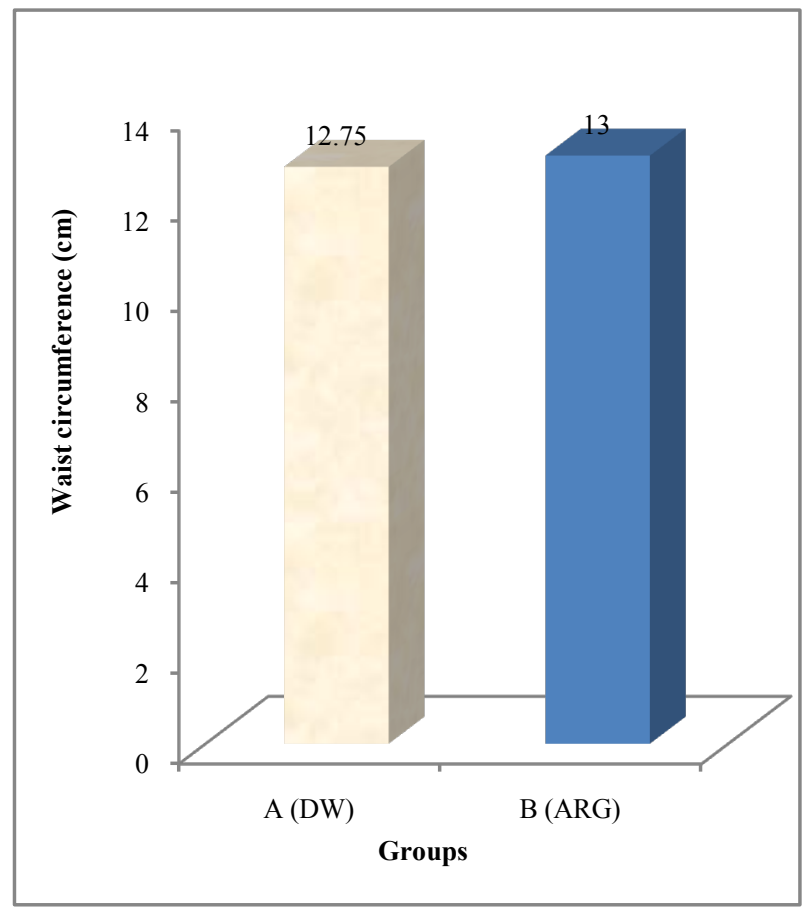

Figure 1. Influence of DW and ARG on Waist circumference of rats

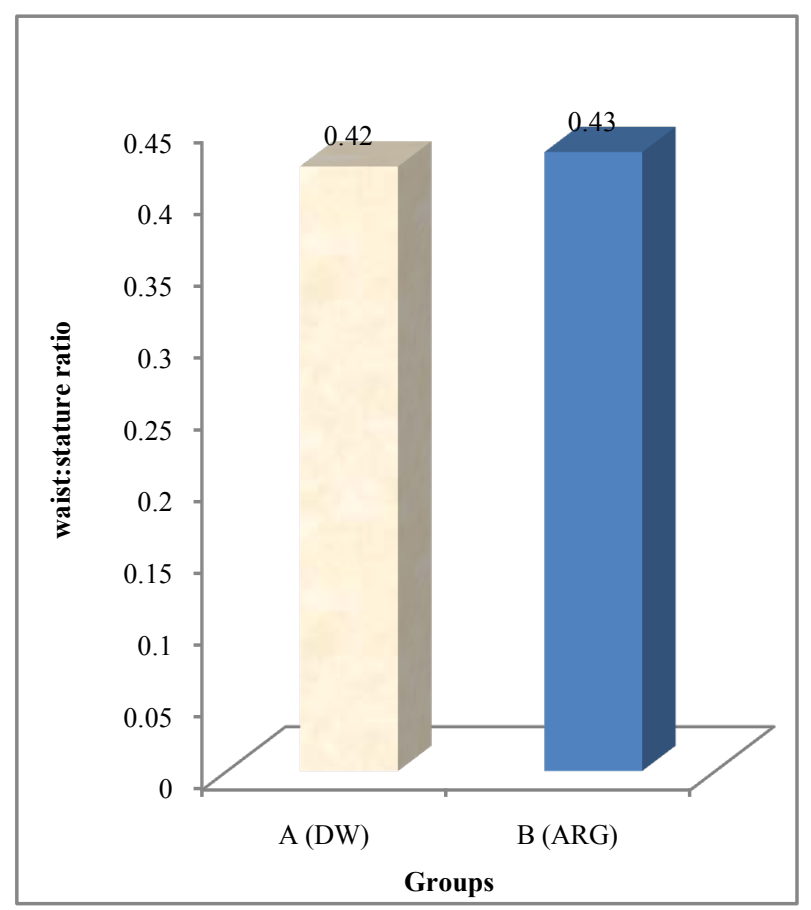

Figure 2. Effect of DW and ARG on Waist:Stature ratio of rats 


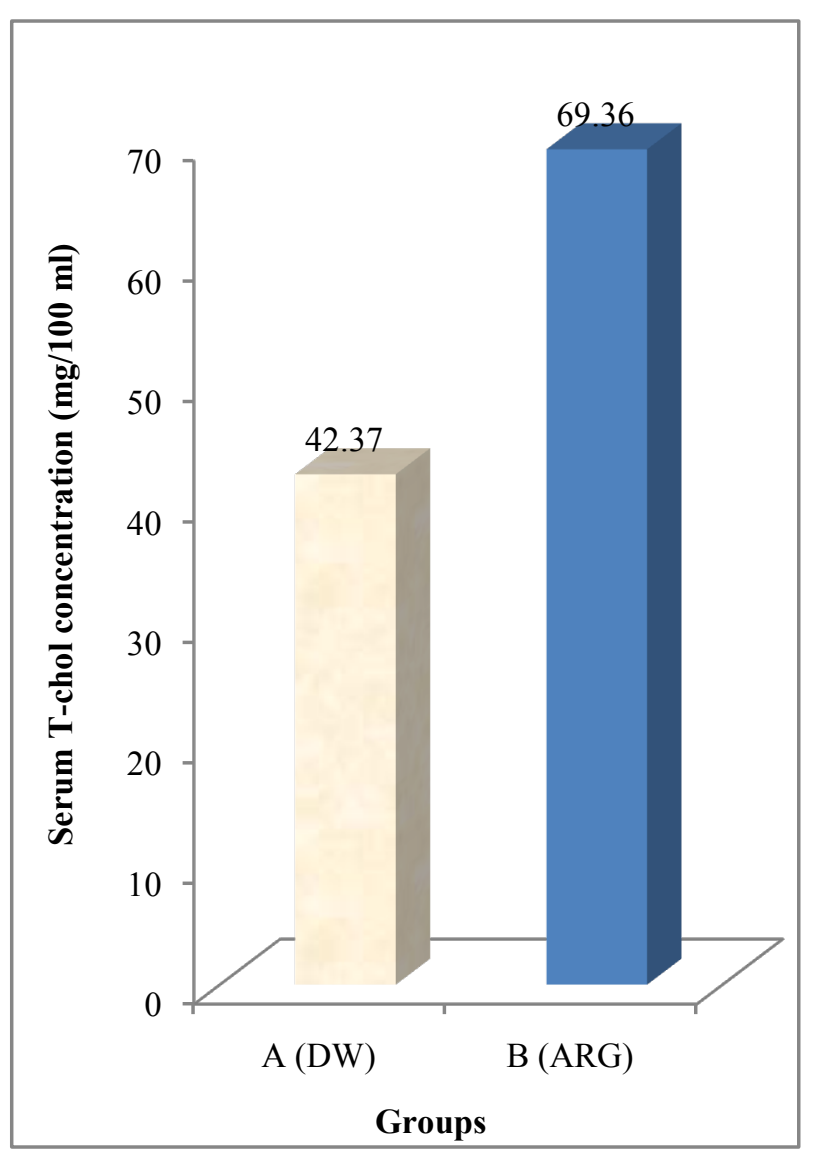

Figure 3. Effect of DW and ARG on serum T-chol concentration of rats

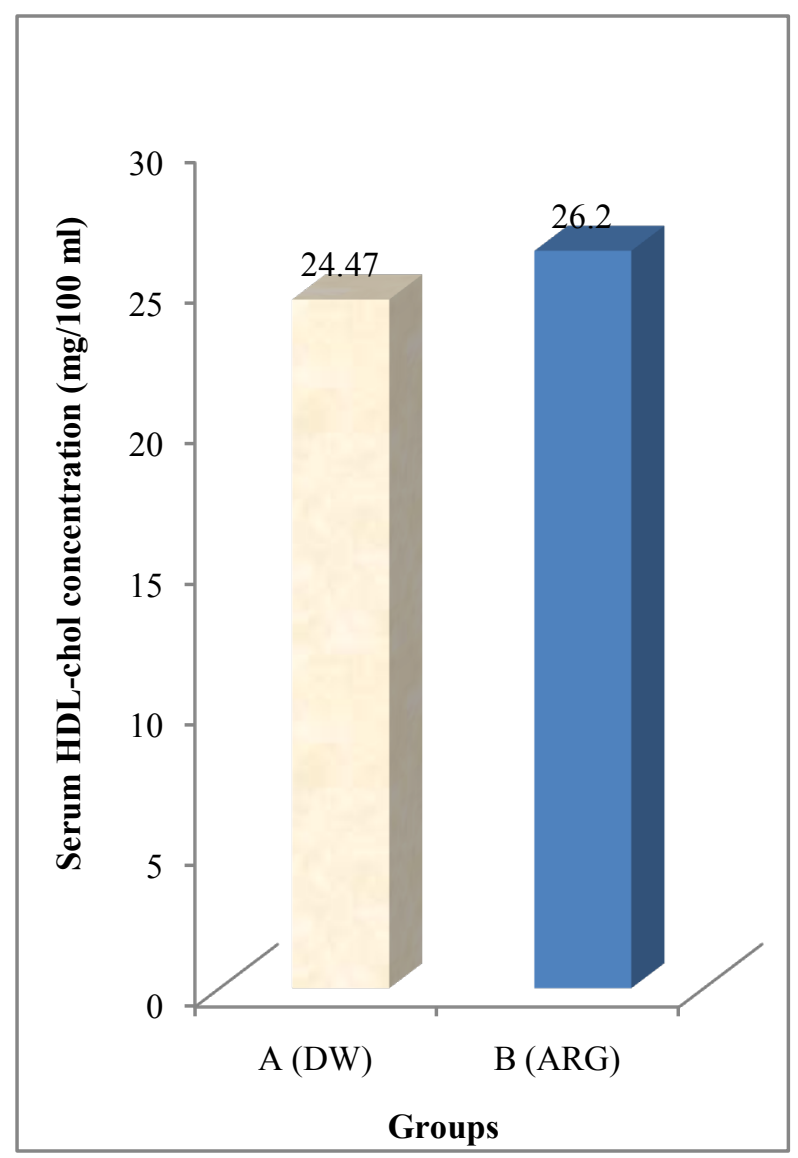

Figure 4. Effect of DW and ARG on HDL-chol concentration of rats

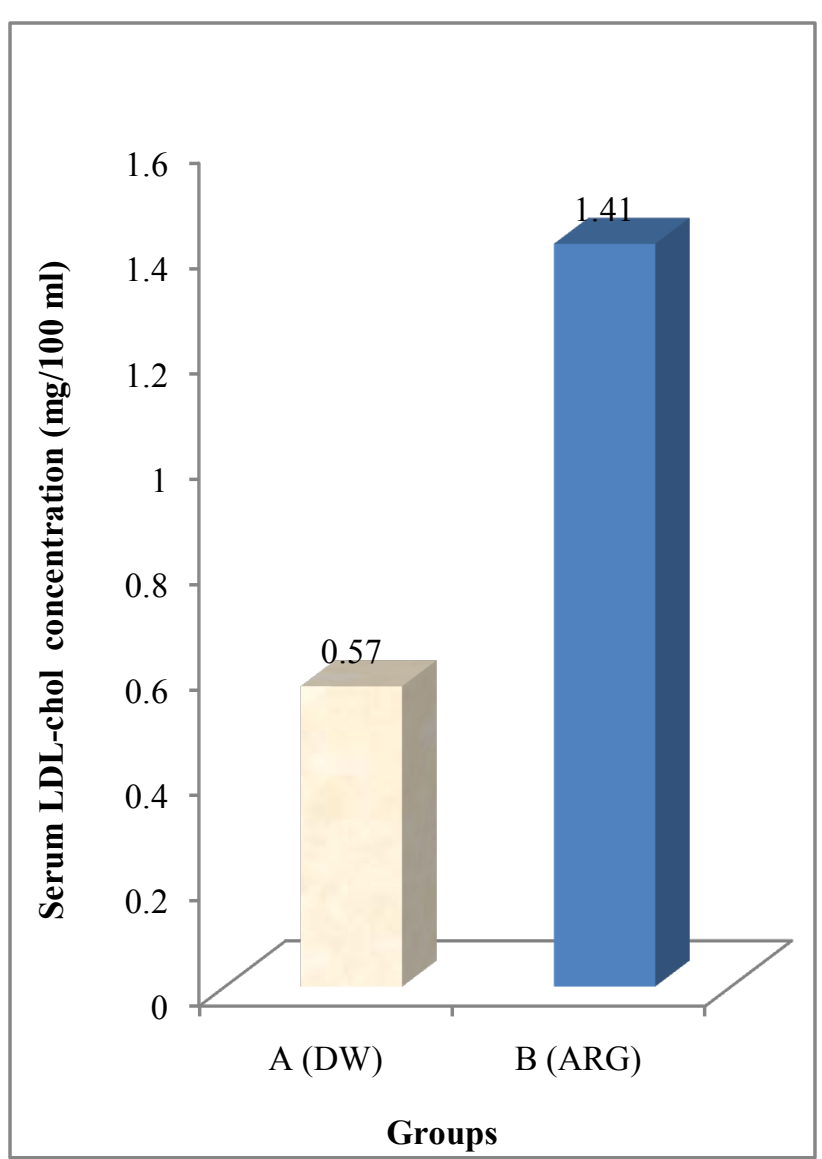

Figure 5. Effect of DW and ARG on LDL-chol concentration of rats

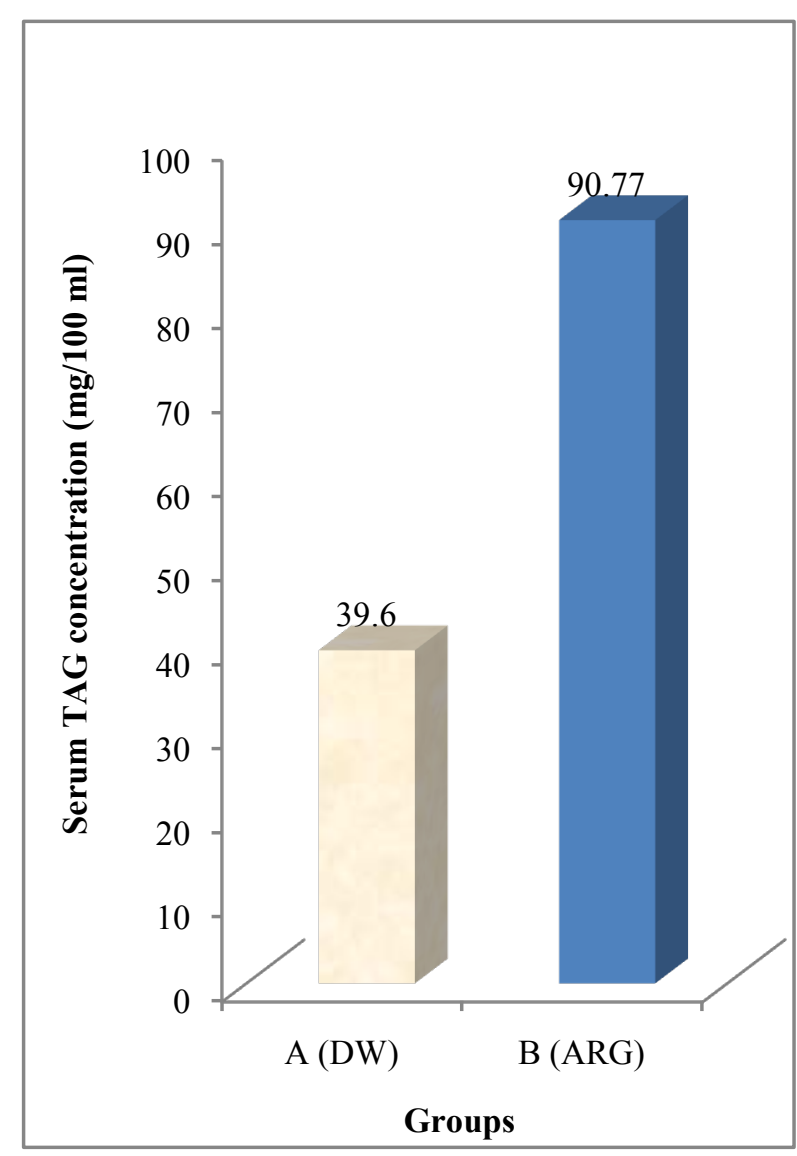

Figure 6. Effect of DW and ARG on TAG concentration of rats 


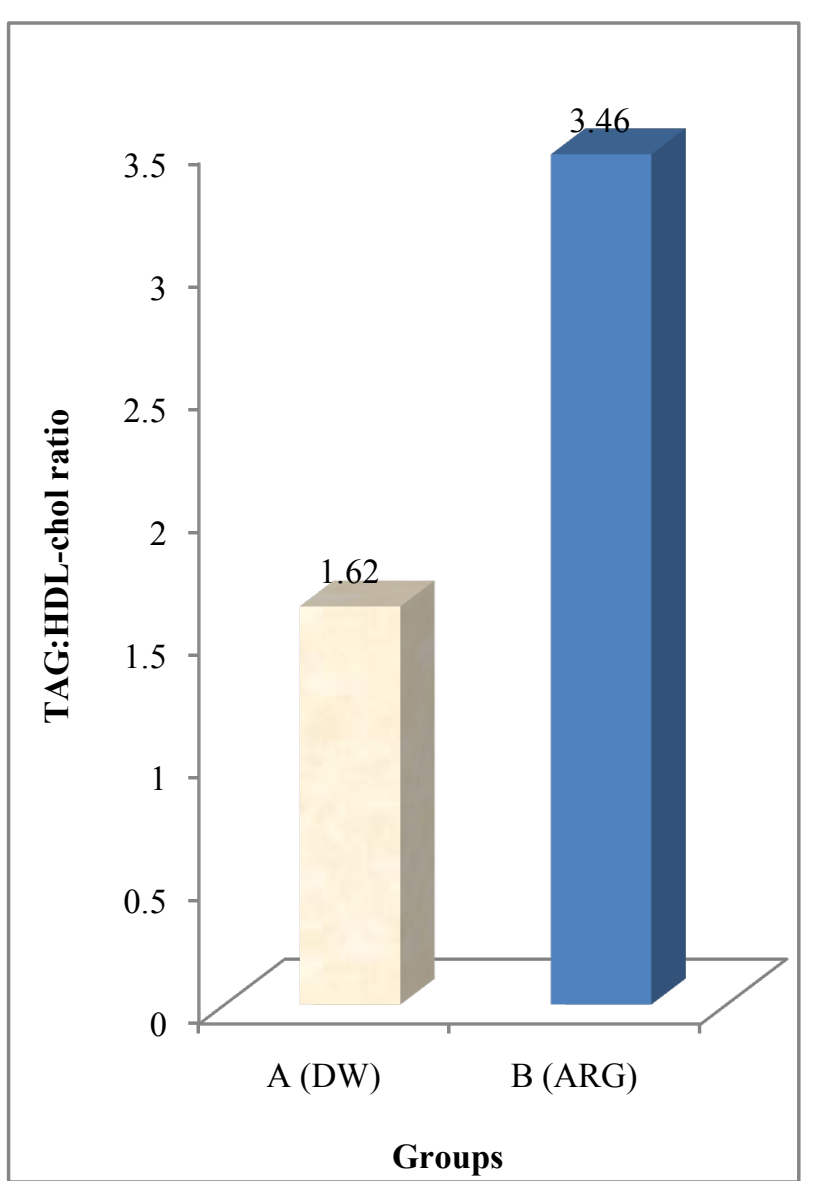

Figure 7. Effect of DW and ARG on serum TAG:HDL-chol ratio of rats

\section{Discussion}

Abdominal obesity or high waist circumference and lipid disorder are among the risk factors for the development of metabolic syndrome (MES) in animals[2]. Following the association of a significant reduction in nitric oxide with the pathophysiology of MES[16], it was speculated that L-arginine, a major precursor in the synthesis of NO, may improve MES in animals[28]. This study therefore, aimed to ascertain the effect of ARG on markers of MES related to abdominal obesity and lipid metabolism.

Waist circumference and waist:stature ratio increased in ARG group, reflecting insulin resistance[29], increased adiposity[30] or incidence of MES[31]. In particular, increased waist:stature ratio (a marker of abdominal obesity) was associated with cardiovascular diseases[32], type 2 diabetes mellitus[33,34] and MES[35,36]. In apparent support of this finding, TAG:HDL-chol ratio, another marker of abdominal obesity[1] increased in ARG-fed rats. Thus, ARG may worsen MES related to increased abdominal obesity in the female rats.

Increase in T-chol concentration occurred in diabetes mellitus and heart diseases[26]. Thus, lowering serum total cholesterol prevented cardiovascular disease[37] a major risk factor for MES in animals. In this study, exposure of the female rats to ARG increased $(\mathrm{p}<0.01) \mathrm{T}$-chol concentration in the rats' serum, suggesting adverse influence on cholesterol metabolism and possibly MES related to abnormal cholesterol metabolism in the rats. Thus, ARG may worsen increased T-chol contribution to MES in the female animals.

Furthermore, the ARG-induced increase $(p<0.01)$ in serum LDL-chol concentration in this study underscores adverse response on MES associated with compromised cholesterol metabolism in the animals, perhaps resulting from cardiovascular risks[38]. Low density lipoproteins play a key, but adverse, role in cholesterol transfer and metabolism[39] by carrying the circulating cholesterol from the liver to the peripheral tissues[26]. LDL-chol is therefore atherogenic[40]; hence it is a risk factor for cardiovascular disease[41] by increasing triacylglycerol production via enhanced fatty acid accumulation in adipocytes[42]. Thus, ARG may worsen increased LDL-chol contribution to MES in female animals.

Consistent with the present result on LDL-chol concentration, data reveal that exposure of the rats to ARG increased $(p<0.01)$ triacylglycerol (TAG) concentration in the rats' serum, indicating possible MES feature[43,2,15]. Increased TAG concentration was a risk factor for arteriosclerosis[26], and possibly MES. Thus, exposing the female rats to ARG may aggravate MES related to their increased TAG concentration.

Exposing ARG to the female rats had a significant increase $(\mathrm{p}<0.01)$ on the serum high density lipoprotein cholesterol (HDL-chol) concentration of the rats. This could be reflective of protective influence on MES in the rats. Increasing HDL-cholesterol protected against the development of cardiovascular disease[37,43,2], possibly by transporting cholesterol from the peripheral tissues back to the liver[26]. Thus, ingesting ARG by rats may improve MES related to an increase in HDL-chol.

Generally, lipid disorder is a major risk factor for the development of MES in animals. Lipids are atherogenic and the deposition of plaques in the blood vessels following their increase narrows the blood vessels resulting to high blood pressure or hypertension which is a major component of MES. However, the apparent ARG-induced benefit on MES related to HDL-chol metabolism may not be significant considering the observed ARG-induced adverse influence on other MES parameters related to lipid metabolism of the rats. Thus, exposure of the rats to ARG may elicit much adverse influence on lipid metabolism that may worsen MES hence it is not advisable to use ARG in the management of MES related to impaired lipid metabolism in female rats.

In conclusion, these data suggest that ARG may worsen MES probably by eliciting adverse influence on abdominal obesity and lipid metabolism as indicated by the apparent ARG- induced adverse influence on the studied markers of abdominal obesity and lipid metabolism in the female rats. This may negate the hoped-for potential of ARG in the management of MES in animals; hence further studies in this direction are needed for corroboration or otherwise. 


\section{REFERENCES}

[1] E. Girotto S.M. Andrade and M.A. Cabrera, Prevalence of abdominal obesity in hypertensive patients registered in a Family Health Unit, Arq. Bras. Cardiol., 94(6) 754-762, 2010.

[2] E.J. Gallagher D. Leroith and E. Karnieli, Insulin resistance in obesity as the underlying cause for the metabolic syndrome, Mt. Sinai J. Med., 77(5) 511-23, 2010.

[3] P.C. Deedwania and R. Gupta, Management issues in the metabolic syndrome, J. Assoc. Physicians India, 4 797-810, 2006.

[4] W.F. Wilson R. Agostino H. Parise L. Sullivan and J. Meigs, Metabolic Syndrome as a precursor of Cardiovascular Disease and Type 2 Diabetes Mellitus, Circulation, 112 3066-3072, 2005

[5] S. Azhar, Peroxisome proliferator-activated receptors, metabolic syndrome and cardiovascular disease, Future Cardiol., 6(5) 657-691, 2010.

[6] A.A. Siddiqui, Metabolic Syndrome and its association with colorectal cancer: A review, Am. J. Med. Sci., 341(3) 227-231, 2011.

[7] C. Pelucchi E. Negri R. Talamini F. Levi A. Giacosa A. Crispo E. Bidoli M. Montella S. Franceschi C. La Vecchia, Metabolic syndrome is associated with colorectal cancer in men, Eur. J. Cancer., 46(10) 1866-1872, 2010.

[8] V. Rosato A. Zucchetto C. Bosetti L.D. Maso M. Montella C. Pelucchi E. Negri S. Franceschi and C. La Vecchia, Metabolic syndrome and endometrial cancer risk, Ann. Oncol., 22(4) 884-889, 2011

[9] I. Capasso E. Esposito F. Pentimalli A. Crispo M. Montella M. Grimaldi M. De Marco E. Cavalcanti M. D'Aiuto, A. Fucito G. Frasci N. Maurea G. Esposito T. Pedicini A. Vecchione G. D'Aiuto and A. Giordano, Metabolic syndrome affects breast-cancer risk in postmenopausal women: National Cancer Institute of Naples experience, Cancer Biol. Ther., 10(12) 1240-1243, 2011.

[10] G. Mugnai, Pathophysiological links between obstructive sleep apnea syndrome and metabolic syndrome, G. Ital. Cardiol. (Rome), 11(6), 453-459, 2010.

[11] O. Kozumplik S. Uzun and M. Jakovljević, Metabolic syndrome in patients with psychotic disorders: diagnostic issues, comorbidity and side effects of antipsychotics, Psychiatr. Danub., 22(1) 69-74, 2010.

[12] A.M. Gotto Jr. G.L. Blackburn G.E. Dailey A.J. Garber S.M. Grundy and B.E. Sobel, The metabolic syndrome: A call to action, Coron. Artery Dis., 17 77-80, 2006.

[13] S.M. Grundy, Metabolic syndrome pandemic, Arterioscler. Thromb. \& Vasc. Biol., 28(4) 629-636, 2008.

[14] C. Mangat N.K. Goel D.K. Walia N. Agarwal M.K. Sharma J. Kaur R. Singh and G. Singh, Metabolic Syndrome: a challenging health Issue in highly urbanized Union Territory of north India, Diabetology \& Metabolic Syndrome, 2 19, 2010.

[15] S. Kilic N. Yilmaz G. Erdogan M. Aydin N. Tasdemir M. Doganay and S. Batioglu, Effect of non-oral estrogen on risk markers for metabolic syndrome in early surgically menopausal women, Climacteric, 13(1) 55-62, 2010

[16] C.D. Garlichs J. Beyer H. Zhang A. Schmeisser K. Plötze A. Mügge S. Schellong and W.G. Daniel, Decreased plasma concentrations of L-hydroxy-arginine as a marker of reduced NO formation in patients with combined cardiovascular risk factors, J. Lab. Clin. Med., 135(5) 419-25, 2000.

[17] S. Moncada R.M. Palmer and E.A. Higgs, Nitric oxide: physiology, pathophysiology and pharmacology, Pharmacol. Rev., 43(2) 109-142, 1991.

[18] D. Lann and D. LeRoith, Insulin resistance as the underlying cause for the metabolic syndrome, Medical Clinics of North America, 91(6) 1063-1077, 2007.

[19] W.E. Marshal, Amino acids, peptides and proteins. In: Functional Foods: Designer Foods, Pharmafoods, Nutraceuticals. Goldberg, I., (Eds.). Chapman and Hall, Thomson Publishing, New York, pp. 242-260, 1994.

[20] B.T. Alexander M.T. Llinas W.C. Kruckeberg and J.P. Granger, L-Arginine attenuates hypertension in pregnant rats with reduced uterine perfusion pressure, Hypertension, 43(4) $832-836,2004$

[21] A.C.C. Egbuonu O. Obidoa C.A. Ezeokonkwo P.M. Ejikeme and L.U.S. Ezeanyika, Some biochemical effects of sub-acute oral administration of L-arginine on monosodium glutamate-fed Wistar albino rats 1: Body weight change, serum cholesterol, creatinine and sodium ion concentrations, Toxicol. \& Environ. Chem., 92(7) 1331-1337, 2010a.

[22] A.C.C. Egbuonu C.A. Ezeokonkwo P.M. Ejikeme O. Obidoa and L.U.S. Ezeanyika, Some biochemical effects of sub-acute oral administration of L-arginine on monosodium glutamate-fed Wistar albino rats 2: Serum alkaline phosphatase, total acid phosphatase and aspartate aminotransferase activities, Asian J. Biochem., 5(2) 89-95, 2010b.

[23] A.C.C. Egbuonu L.U.S. Ezeanyika P.M. Ejikeme and O. Obidoa, Histomorphologic alterations in the liver of male Wistar rats treated with L-arginine glutamate and monosodium glutamate, Res. J. Environ. Toxicol., 4(4) 205-213, 2010c.

[24] American Physiological Society (APS), Guiding principles for research involving animals and human beings, Am. J. Physiol. Regul. Integr. Comp. Physiol., 283 281-283, 2002.

[25] A. Zlatkis B. Zak and J. Boyler, Colorimetric determination of cholesterol in serum, J. Lab. Clin. Med., 41 p.43c, 1953.

[26] J. Ochie and A. Kolhatkar, Medical laboratory science: theory and practice, Tata McGraw-Hill Publishing Company Limited, New Delhi, India, pp. 1-1338. ISBN-13:978-0-07-4 63223-9, 2008

[27] L.A. Carlson, Determination of serum triglycerides, J. Athero. Res., 3 334-336, 1963.

[28] L.U.S. Ezeanyika and A.C.C. Egbuonu, Impact of nitric oxide and insulin resistance on the pathophysiology of the metabolic syndrome: Possible role of L-arginine and glutamate, Journal of Medicine and Medical Sci., 2(2) 657-662, 2011.

[29] Y.M. Park H.S. Kwon S.Y. Lim J.H. Lee K.H. Yoon H.Y. Son H.W. Yim and W.C. Lee, Optimal Waist Circumference Cutoff Value Reflecting Insulin Resistance as a Diagnostic Criterion of Metabolic Syndrome in a Nondiabetic Korean Population Aged 40 Years and Over: The Chungju Metabolic Disease Cohort (CMC) Study, Yonsei Med. J., 51(4) 511-518, 2010.

[30] L. Wang Y. Tao Z. Xie X. Ran M. Zhang Y. Wang X. Luo M. 
Hu W. Gen H. Wufuer L. Li J. Ren and X. Mao, Prevalence of metabolic syndrome, insulin resistance, impaired fasting blood glucose, and dyslipidemia in Uygur and Kazak populations, The Journal of Clinical Hypertension, 12(9) 741-745, 2010.

[31] G.D. Pimentel S.T. Arimura B.M. de Moura M.E.R. Silva and M.V. de Sousa, Short-term nutritional counseling reduces body mass index, waist circumference, triceps skinfold and triglycerides in women with metabolic syndrome, Diabetology \& Metabolic Syndrome, 2 13, 2010.

[32] K. Ohashi N. Ouchi and Y. Matsuzawa, Adiponectin and Hypertension, Am. J. Hypertens., 24(3) 263-269, 2011.

[33] R.S. Padwal and A.M. Sharma, Prevention of cardiovascular disease: obesity, diabetes and the metabolic syndrome, Can. J. Cardiol., 26(Suppl C) 18C-20C, 2010.

[34] F. Chaabo A. Pronczuk E. Maslova and K.C. Hayes, Nutritional correlates and dynamics of diabetes in the Nile rat (Arvicanthis niloticus): a novel model for diet-induced type 2 diabetes and the metabolic syndrome, Nutr. Metab. (Lond)., 7 29, 2010.

[35] S.L. Rodrigues M.P. Baldo and J.G. Mill, (2010). Association of waist-stature ratio with hypertension and metabolic syndrome: Population-based study, Arq. Bras. Cardiol., 95(2) 186-191, 2010.

[36] J.S. Mokha S.S. Srinivasan P. Dasmahapatra C. Fernandez W. Chen J. Xu and G.S. Berenson, Utility of waist-to-height ratio in assessing the status of central obesity and related cardiometabolic risk profile among normal weight and overweight/ obese children: The Bogalusa Heart Study, BMC Pediatr., 10(1) $73,2010$.
[37] F.S. Lira J.C. Rosa A.E. Lima-Silva H.A. Souza E.C. Caperuto M.C. Seelaender A.R. Damaso L.M. Oyama and R.V.T. Santos, Sedantary subjects have higher PAI-1 and lipoproteins levels than highly trained athletes, Diabetology and Metabolic Syndrome, 2 7-11, 2010.

[38] L.M. Ntyintyane V.R. Panz F.J. Raal and G.V. Gill, Postprandial lipaemia, metabolic syndrome and LDL particle size in urbanized South African blacks with and without coronary artery disease, Q. J. Med., 101 111-119, 2008.

[39] Bairakatri, E.T., Seferiadis, K.I. and Elisaf, M. (2005). Evaluation of methods for the measurement of low-density lipopretin cholesterol. J. Cardiovasc. Pharmacol. Therapeut., 10:45-54. doi:10:1177/10742480501000106.

[40] M.A. Austin, Triglyceride, small, dense low-density lipoprotein, and the atherogenic lipoprotein phenotype, Curr. Atheroscler. Rep., 2 200-207, 2000.

[41] E. Oda and R. Kawai, Low-density lipoprotein (LDL) cholesterol is associated with preclinical chronic kidney disease (CKD) in Japanese men, Intern. Med., 49(8) 713-719, 2010.

[42] R.H. Knopp and P. Paramsothy, Oxidized LDL and abdominal obesity: a key to understanding the metabolic syndrome, Am. J. Clin. Nutr., 83(1) 1-2, 2006.

[43] National Cholesterol Education Program (NCEP) Report, Expert Panel on Detection, Evaluation, and Treatment of High Blood Cholesterol in Adults: Executive summary of the third report of the National Cholesterol Education Program (NCEP) (Adult Treatment Panel III), Am. Med. Assoc., 285 2486-2497, 2001. 